\section{IUPAC Executive Director Search}

T he International Union of Pure and Applied Chemistry (IUPAC) is seeking to appoint a new executive director to replace Dr. John W. Jost, who will retire towards the end of 2010. The executive director reports to the president through the secretary general (and for financial matters through the treasurer). The executive director is responsible for the administration of the business of the Union, including management of the Union's Secretariat, its publications, finance, interaction with National Adhering Organizations that comprise the Union, organization of biennial General Assemblies and Congresses, and the provision of support for the officers and governing bodies of the Union. The IUPAC Secretariat has a current staff of five and is located in Research Triangle Park, North Carolina, USA. Extensive travel outside the United States is required.

The executive director must have the following:

a substantial background in chemistry (doctoral degree preferred)
- ability to organize, manage, recruit, and interact effectively with workers in a small office environment

- proficiency in information technology

- ability to formulate and execute the IUPAC budget (currently USD 1.5 million p.a.)

- ability to communicate effectively and diplomatically with a large number of scientific leaders throughout the world

A detailed job description is available on request. Salary is commensurate with experience. Only applicants with permanent residence status in the USA can be considered. The desired appointment date is early in 2010 to allow for a period of overlap with Dr. Jost.

Interested applicants are asked to send their applications, including $\mathrm{CVs}$ and the names and contact details of three referees, by e-mail to the Secretary General at <secretariat@iupac.org>, by 31 May 2009.

\section{Val Metanomski Remembered*}

ongtime IUPAC member Val Metanomski died on 11 December 2008. He was an expert in the development and application of polymer nomenclature, and was one of the authors of the IUPAC Purple Book, the Compendium of Polymer Terminology and Nomenclature.

Val's long and sterling service to IUPAC, which included serving on the Commission on Macromolecular Nomenclature and Subcommittee on Polymer Terminology and chemical nomenclature in general (ICTNS), spanned more than 30 years. He made a memorable effort in bringing together and editing the first edition of the Purple Book and his thoroughness and dedication kept the work on the second edition alive at a critical time, particularly in the 1990s.

IUPAC colleagues remember $\mathrm{Val}$ as an extremely trustworthy and dependable colleague who approached his work with academic rigor, perspicac-

* Most of the biographical material for this article was extracted from Nontraditional Careers for Chemists-New Formulas in Chemistry, by Lisa M. Balbes, Oxford University Press 2007, ISBN-13 9780195183665, reproduced by permission of Oxford University Press, Inc. ity, maturity, and humor. He will be sorely missed, both as a colleague and a friend.

Val Metanomski was a senior scientific information specialist with the Chemical Abstract Service (CAS), an organization he served for 44 years. He was responsible for generating and editing Chemical Abstract Index names for polymers selected by other specialists from the primary literature (journal articles and

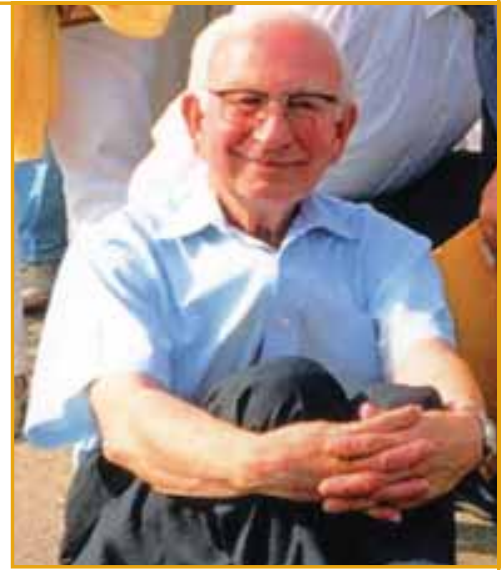

Val Metanomski during the IUPAC General Assembly held in Berlin, Germany, in August 1999. (photo by Koichi Hatada) patents) for inclusion in the CAS database (Registry File, CA File, etc.). On a typical day, Val examined several queues of chemical structures, sorted and accessible by the CAS registry numbers, at various stages in the naming process. Chemical substances (compounds) are selected for indexing by document analysts who read full original journal papers, conference proceedings, and patents. Compounds that renew, or have new information reported about them, are selected for inclusion in the databases. 
Once a compound was selected, Val's job was to generate the CA index name, according to the CAS nomenclature rules. The entire process, from selecting a compound to releasing the verified name, can take a month. Val explained, "Polymer-macromolecularnomenclature is quite challenging, and rules have to be continually updated as new types of polymers are synthesized. Polymers are actually given two types of names, source-based names expressed in terms of monomers-starting materials, and structure-based names expressed in terms of structural-constitutionalrepeating units, if known."

Val's career choice was unconventional. After serving in the army during World War II, Val found that available grants were given only to those pursuing careers in practical sciences; so, Val chose chemistry for his undergraduate major. Val become interested in chemical literature, information retrieval, and related problems as early as the fourth year of his undergraduate studies in England. Having received a BS in chemical engineering, Val moved to Canada and worked for a water-treatment company. After six years in industry, Val decided to go back to school and continue toward a Ph.D. in the same field.

Upon receiving his doctorate in 1964, Val applied for a job with CAS in Columbus, Ohio, where he worked for the rest of his career. During that time, his career path paralleled that of the organization, which went from the printed-product environment to the modern online and Internet environment, and he adapted to and embraced the changes as they came along.

As time went on, he became involved with a variety of projects aimed at converting the traditional manual operations into highly automated processes. For example, Val assisted editors in developing vocabulary-control systems for both abstracts and index entries. Ensuring that a consistent vocabulary was used throughout all publications simplified the automation and electronic processing of documents. Val also was responsible for managing an editorial planning and development department. He took an active part in the transition from the printed-product environment to the modern online and Internet environment of chemical information.

Val's advice to those interested in a career in chemical information was that "knowledge of the tools available for chemical-information retrieval, and knowledge of chemistry to assign potential-value ratings to the information retrieved" are crucial.
For careers in "chemical information," or "cheminformatics," Val recommended first getting a basic degree in chemistry (attending a three-year college program leading to a B.Sc. would be fine), then a master's degree at an information-science or librarianship school.

On 20 May 2008, Val was presented with the 2008 Columbus Section of the American Chemical Society award in recognition of achievements extending over a lifetime of service to chemical information. At the award banquet held in his honor, Val talked of his personal "Road Less Traveled" and in his closing observation, he answered the question, Is there anything from the old days that was better than today?

"Perhaps it was also serendipity, many years ago," said Jeffrey Wilson from CAS, "when a job opening at CAS caught the attention of a chemist at a crossroad in his career. We can all be glad that opportunity was not lost."

"Nowadays," said Val, "when searchers, sitting at their own terminals connected to a plethora of databases with the ability to use clever front-end software, pose a well-defined question, they get instantly highly relevant answers, and nothing more. In the old days, browsing through the printed issues of abstracts or through tables of contents of primary journals allowed you to see, through a corner of your eye, something else on the same page, something of some obvious interest or even related to your topic. That was serendipity at its best. This capability has been lost altogether."

"Perhaps it was also serendipity, many years ago," said Jeffrey Wilson from CAS, "when a job opening at CAS caught the attention of a chemist at a crossroad in his career. We can all be glad that opportunity was not lost."

Val's wife of 44 years, Helena, died soon after him on January 17, 2009. He is survived by a daughter, Marianne and two grandchildren. 